\title{
Hypothetical Choice, Egalitarianism and the Separateness of Persons
}

\author{
KEITH HYAMS \\ University of Warwick
}

\begin{abstract}
Luck egalitarians claim that disadvantage is worse when it emerges from an unchosen risk than when it emerges from a chosen risk. I argue that disadvantage is also worse when it emerges from an unchosen risk that the disadvantaged agent would have declined to take, had he or she been able to do so, than when it emerges from an unchosen risk that the disadvantaged agent would not have declined to take. Such a view is significant because it allows both luck egalitarians and prioritarians to respond to Voorhoeve and Fleurbaey's charge that they fail to accommodate intuitions about the moral relevance of interpersonal boundaries - the so-called separateness of persons objection. I argue that the view is plausible independently of its ability to answer the separateness of persons objection, and is a natural extension of the luck egalitarian concern with the impact of unchosen circumstance.
\end{abstract}

\section{INTRODUCTION}

The separateness of persons objection claims that certain ethical views disregard intuitions about the moral relevance of interpersonal boundaries. Utilitarians have long been charged with such a failing. More recently, Otsuka and Voorhoeve have charged that prioritarians, those who think that, in Parfit's words, 'benefiting people matters more the worse off these people are', are also vulnerable to the objection. ${ }^{1}$ In yet a further deployment of the objection, Voorhoeve and Fleurbaey now charge that a third view is also guilty of failing to accommodate intuitions about the moral relevance of interpersonal boundaries. ${ }^{2}$ That view is brute luck egalitarianism, the recently popular view that disadvantage - by which is meant comparative disadvantage - that is the result of unchosen circumstance, is worse than disadvantage that is not the result of unchosen circumstance. ${ }^{3}$

1 M. Otsuka and A. Voorhoeve, 'Why It Matters That Some Are Worse Off Than Others: An Argument Against the Priority View', Philosophy \& Public Affairs 37 (2009), pp. 171-99; D. Parfit, 'Equality and Priority', Ratio 10 (1997), pp. 202-21.

2 A. Voorhoeve and M. Fleurbaey, 'Egalitarianism and the Separateness of Persons', Utilitas 24 (2012), pp. 381-98.

3 Although the term 'luck egalitarianism' is more commonly used, some authors have begun to refer to 'brute luck egalitarianism' in order to clarify that unchosen luck, rather

(c) Cambridge University Press 2015. This is an Open Access article, distributed under the terms of the Creative Commons Attribution licence (http://creativecommons.org/ licenses/by/3.0/), which permits unrestricted re-use, distribution, and reproduction in any medium, provided the original work is properly cited. Utilitas Vol. 27, No. 2, June 2015

doi:10.1017/S0953820814000363 
Several authors have replied to the separateness of persons objection on behalf of prioritarianism. ${ }^{4}$ To my knowledge, no one has yet replied to the objection on behalf of brute luck egalitarianism. In what follows I offer such a response, by describing a version of brute luck egalitarianism that does not encounter the separateness of persons objection. As I explain, we can also describe a prioritarian variant of the view, thereby offering prioritarians another way to avoid the objection. Both positions are interesting not only in so far as they provide answers to the separateness of persons objection, but also because they help us to achieve a clearer understanding of how we should evaluate the badness of any given disadvantage, and how we should make deontic recommendations on the basis of those evaluations.

The article begins by setting out Voorhoeve and Fleurbaey's charge that brute luck egalitarianism cannot accommodate intuitions about the separateness of persons, and by discussing some possible egalitarian responses to the charge. I then describe a new version of brute luck egalitarianism (and its prioritarian relation) that is sensitive to hypothetical choices about risk, and I explain the independent appeal of such a view. I show how the stated view is able to answer the separateness of persons objection, and I discuss whether the view might need to be modified to accommodate cases involving children.

\section{THE SEPARATENESS OF PERSONS OBJECTION}

Why might brute luck egalitarians appear vulnerable to the separateness of persons objection? Before answering this question, it will help, first, to clarify the nature of the charge, by distinguishing three different ways in which a particular moral view might be thought

than chosen luck, is the primary object of egalitarian concern. More recent versions of brute luck egalitarianism include the qualification that particular background conditions must be satisfied in order for choice to render disadvantage less bad than it would otherwise have been, such as the requirement that there was a reasonable alternative to the chosen option. The presence of such a qualification can be assumed in what follows, and makes no difference to the overall argument. Note also that, for clarity's sake, I frame brute luck egalitarianism in the present article mostly in telic terms, that is, as a view concerned with the badness or unfairness of disadvantage. Brute luck egalitarianism can, however, be recast in deontic terms, as a view about how one ought to act in order to avoid bringing about unjust disadvantage. The present arguments would apply in equal measure to such a view. For the distinction between telic and deontic egalitarianism, see Parfit, 'Equality or Priority'.

${ }^{4}$ R. Crisp, 'In Defence of the Priority View: A Response to Otsuka and Voorhoeve', Utilitas 23 (2011), pp. 105-8; A. Williams, 'The Priority View Bites the Dust?', Utilitas 24 (2012), pp. 315-31; M. O’Neill, 'Priority, Preference, and Value', Utilitas 24 (2012), pp. 332-48; T. Porter, 'In Defence of the Priority View', Utilitas 24 (2012), pp. 349-64; D. Parfit, 'Another Defence of the Priority View', Utilitas 24 (2012), pp. 399-440; G. Bognar, 'Empirical and Armchair Ethics', Utilitas 24 (2012), pp. 467-82; M. Rendall, 'Priority and Desert', Ethical Theory and Moral Practice 16 (2013), pp. 939-51. 
to disregard intuitions about the moral relevance of interpersonal boundaries. $^{5}$

According to the first interpretation of the separateness of persons objection, the objection is that a particular moral view is problematic because it resolves interpersonal conflicts in a way that is intuitively impermissible, by virtue of its ignoring intuitions about the moral relevance of interpersonal boundaries. Utilitarianism, for example, confronts the first version of the objection when it recommends giving a resource to a well-off agent over a badly-off agent on the sole ground that the well-off agent will derive slightly more benefit from the resource than the badly-off agent. The second interpretation claims that a particular moral view is objectionable because it is indifferent between alternative possible distributive outcomes when, according to intuition, we ought to prefer one outcome over another for reasons that have to do with the moral relevance of interpersonal boundaries. Utilitarianism confronts this version of the objection when it expresses indifference whether a resource be given to a badly-off agent or a welloff agent, both of whom will derive the same amount of benefit from the resource. The third interpretation of the objection, which unlike the first two interpretations focuses on the justification for a view rather than the view itself, claims that the justification for a particular moral view is objectionable because it implausibly extends an intrapersonal principle to the resolution of interpersonal conflicts. Utilitarianism confronts the third version of the objection if it looks to an intrapersonal principle to justify its claim that we should maximize expected utility in interpersonal cases, as in Mill's famous 'proof' of utilitarianism: 'that each person's happiness is a good to that person, and that the general happiness, therefore, is a good to the aggregate of all persons'. ${ }^{6}$

In what follows I shall respond to the charge that brute luck egalitarianism is vulnerable to the first of the above versions of the separateness of persons objection. I focus on the first version of the objection for two reasons. First, because Voorhoeve and Fleurbaey's examples, as described below, are most readily interpreted as illustrations of this version of the objection. Second, because this is the version that appears to pose the strongest prima facie threat to brute luck egalitarianism. Unlike utilitarianism, brute luck

${ }^{5}$ I do not insist that these three interpretations of the objection exhaust the possible ways in which a view might fail to be sensitive to the moral relevance of interpersonal boundaries. Nor do I mention ways in which each of the three interpretations identified might be further subdivided. For further discussion of different versions of the separateness of persons objection as applied to prioritarianism, see Porter, 'In Defence of the Priority View'; M. Otsuka, 'Prioritarianism and the Separateness of Persons', Utilitas 24 (2012), pp. 365-80.

${ }^{6}$ J. S. Mill (1861), Utilitarianism, ed. R. Crisp (Oxford, 1998), p. 81. 
egalitarianism endorses a principle that is anything but indifferent between possible distributive outcomes, at least in ways that concern the moral relevance of interpersonal boundaries. ${ }^{7}$ Nor does brute luck egalitarianism look to an intrapersonal principle to justify its commitment to equality at the interpersonal level.

Consider, then, Voorhoeve and Fleurbaey's argument for their claim that brute luck egalitarianism is vulnerable to the separateness of persons objection. Voorhoeve and Fleurbaey ask us to imagine the following two scenarios. In the first scenario, the Two-Person Intrapersonal case, there are two children, Albert and Bob, both of whom are visually impaired but not blind. ${ }^{8}$ You, a morally motivated stranger, must decide whether or not to intervene in an unpredictable natural course of events that, if left to run its course, will affect Albert's sight. If you do intervene, Albert's visual impairment will remain unchanged. But if you do not intervene, there is a 50 per cent chance that Albert will become fully sighted and a 50 per cent chance that his visual impairment will become worse. Bob's visual impairment will remain unchanged whether or not you intervene. The loss of utility that Albert would experience if his visual impairment is made worse by the natural course of events $-l$ in the table below - is sufficiently small that the possible gain in utility to Albert just outweighs both the possible loss of utility to Albert and the badness (if any) of the inequality between Albert and Bob that will result from Albert's being made better or worse off than Bob by the natural course of events. ${ }^{9}$ It is therefore just permissible not to intervene in the natural course of events and so to leave Albert exposed to the risk.

The second scenario is Voorhoeve and Fleurbaey's Two-Person Interpersonal case. In this scenario, everything is the same as in the Two-Person Intrapersonal case, except that the possible outcomes of the natural course of events are slightly different. There is now a 50

7 Cf. D. McKerlie, 'Egalitarianism and the Difference between Intrapersonal and Interpersonal Judgments', Egalitarianism: New Essays on the Nature and Value of Equality, ed. N. Holtug and K. Lippert-Rasmussen (Oxford, 2006), pp. 157-73, at 158, n. 2.

8 Voorhoeve and Fleurbaey assume that Albert and Bob are children in order to set aside autonomy-based explanations of how you ought to choose. See section VI below.

9 This is possible only if the badness of disadvantage is not so great that it outweighs the benefit of any possible gain. But as Voorhoeve and Fleurbaey ('Egalitarianism and the Separateness of Persons', p. 390) note, even if this assumption does not hold, we can still frame the problem in terms of brute luck egalitarianism's apparent failure to explain why there are stronger reasons to opt for non-intervention in the intrapersonal case than in the interpersonal case, even if all things considered we should opt for intervention in both cases. Note also that I follow Voorhoeve and Fleurbaey in making no particular assumptions about how utility ought to be measured, except that the measure of utility does not take into account any interest that agents may have in the fairness of the distributive process itself, or in the fairness of the distributive outcomes that it yields. 
Table 1. Voorhoeve and Fleurbaey's Two Person Intrapersonal Trade-off Case and Two Person Interpersonal Trade-off Case

\begin{tabular}{llll}
\hline & & \multicolumn{2}{c}{ State of the world (equiprobable) } \\
\cline { 3 - 4 } Alternative & Person & $s_{1}$ & $s_{2}$ \\
\hline \multirow{2}{*}{ Non-intervention } & Two Person Intrapersonal Trade-off Case & \\
& Albert & 1 & $0.8-l$ \\
Intervention & Bob & 0.8 & 0.8 \\
& Albert & 0.8 & 0.8 \\
& Bob & 0.8 & 0.8 \\
\hline Non-intervention & Two Person Interpersonal Trade-off Case & \\
\cline { 2 - 4 } Intervention & Albert & 0.8 & $0.8-l$ \\
& Bob & 1 & 0.8 \\
& Albert & 0.8 & 0.8 \\
& Bob & 0.8 & 0.8 \\
\hline
\end{tabular}

per cent chance that the natural course of events will cause Bob to become fully sighted whilst having no effect on Albert, and a 50 per cent chance that the natural course of events will cause Albert's visual impairment to become worse whilst leaving Bob unaffected. In each of the two scenarios described, the size of the possible gains and losses in utility are identical, as in table 1.

Voorhoeve and Fleurbaey claim, quite plausibly, that there is a much weaker intuitive case in favour of non-intervention in the interpersonal case than in the intrapersonal case. In the intrapersonal case, they note that you may justify exposing Albert to the risk of having his sight worsened by appealing to the benefit that Albert would enjoy if he instead ended up fully sighted. But in the interpersonal case, the possible benefits are benefits to Bob, not to Albert, and as such provide a much weaker justification for not intervening and leaving Albert exposed to the risk of having his sight worsened. The possible loss to Albert of not intervening, which in the intrapersonal case was just small enough to be outweighed by the possible benefits to Albert, is therefore too large to be outweighed in the interpersonal case by the possible benefit to Bob. More generally, Voorhoeve and Fleurbaey claim, there is an intuitive 'shift in the moral weight of changes in utility between intrapersonal and interpersonal trade-offs'. ${ }^{10}$ This shift, they suggest, reflects the difference played in our moral thinking between the unity of the individual and the separateness of persons.

Like the examples featuring in an earlier, more widely discussed article by Otsuka and Voorhoeve, Voorhoeve and Fleurbaey's examples

10 Voorhoeve and Fleurbaey, 'Egalitarianism and the Separateness of Persons', p. 383. 
provide further illustration of the difficulties that both utilitarians and prioritarians face when trying to accommodate intuitions about the separateness of persons. Both views, as characterized by Voorhoeve and Fleurbaey, mistakenly see an equally strong case for non-intervention in both scenarios. Utilitarians, who value options in proportion to the amount of utility expectably generated by that option, see an equally strong case, because the total expected utility of non-intervention is the same in each scenario. In each scenario, non-intervention would result in one child ending up with his visual impairment unchanged (associated with a utility of 0.8) and either one child ending up fully sighted (associated with a utility of 1) or (with an equal chance in both cases) one child ending up with his visual impairment worsened (associated with a utility of $0.8-l$ ). Prioritarians, claim Voorhoeve and Fleurbaey, also fail to capture the difference in our intuitions about the two cases. As characterized by Voorhoeve and Fleurbaey, on the basis of Parfit's original description of the view, prioritarians value options in proportion to the amount of priority-weighted utility expectably generated by each option, assigning greater value to losses in utility lower down an absolute scale of utility. ${ }^{11}$ Since non-intervention is expected to result in the same amount of priority-weighted utility in both, such a view will see an equal case for non-intervention in both cases.

The charge that neither utilitarianism nor prioritarianism can accommodate the difference in our intuitive judgements about intrapersonal cases and interpersonal cases has been widely discussed, in response to Otsuka and Voorhoeve's original statement of the charge. ${ }^{12}$ Intriguingly, however, Voorhoeve and Fleurbaey's example suggests that it is not only utilitarians and prioritarians who are vulnerable to the separateness of persons objection; rather, their example goes beyond Otsuka and Voorhoeve's original article in suggesting that brute luck egalitarians are also vulnerable to the objection. To see why it does so, recall that brute luck egalitarians believe that disadvantage that is the result of unchosen circumstance (so-called 'brute luck disadvantage') is worse than disadvantage that is not the result of unchosen circumstance (so-called 'option luck

\footnotetext{
11 Parfit, in 'Another Defence of the Priority View', now endorses an alternative version of prioritarianism, which pays attention both to the priority-weighted value of individuals' utility outcomes, and to the priority-weighted value of individuals' expected utilities. This new version of prioritarianism does not encounter the separateness of persons objection, but is vulnerable to an alternative challenge along the lines of that mentioned below in relation to ex ante egalitarianism: the charge that it relies on a morally arbitrary distinction between changes to probability and eventuation of outcomes.

${ }^{12}$ See references in n. 4 above.
} 
disadvantage'). In Voorhoeve and Fleurbaey's example, neither Albert nor Bob have any say in your decision whether or not to intervene, and are unable to intervene in the natural course of events themselves. As such, Voorhoeve and Fleurbaey treat all the possible disadvantage in the example as brute luck disadvantage. Moreover, non-intervention is expected to result in the same amount of comparative disadvantage in both the intrapersonal case and the interpersonal case. In both cases, it is equally likely under non-intervention that either the visual impairment of one child will remain unchanged whilst that of the other child will become worse, or that the visual impairment of one child will remain unchanged whilst the other child will become fully sighted. Voorhoeve and Fleurbaey therefore charge that brute luck egalitarians, like utilitarians and prioritarians, wrongly see as much reason to opt for non-intervention in the interpersonal case as they see in the intrapersonal case.

\section{EGALITARIAN VIEWS THAT AVOID THE OBJECTION}

In the next section I shall describe a way in which brute luck egalitarians might develop their view in an independently plausible direction, thereby avoiding the separateness of persons objection. ${ }^{13}$ I shall suggest that prioritarians might also develop their view in a similar direction in order to avoid the objection. Before I do so, however, I shall first, in the present section, outline three alternative egalitarian responses to the objection, in order to assess their strengths and weaknesses vis-à-vis the response that I recommend in the remainder of the article.

First, as Voorhoeve and Fleurbaey themselves note, the separateness of persons objection is not faced by an egalitarian view that treats the badness of outcome inequality as a function not only of the degree of outcome inequality itself, but also of the degree of ex ante inequality in the distribution of chances that obtained prior to the outcome eventuating. Since non-intervention renders Albert and Bob more ex ante unequal in Voorhoeve and Fleurbaey's interpersonal case than it does in Voorhoeve and Fleurbaey's intrapersonal case, the ex ante view

\footnotetext{
13 It has become something of a joke to refer to the exponential growth in versions of brute luck egalitarianism in recent years (J. Waldron, 'Political Political Theory: An Inaugural Lecture', Journal of Political Philosophy 21 (2013), pp. 1-23, at 21, colourfully compares them to Heinz 57 varieties), betraying the impatience of brute luck egalitarianism's detractors with the energy invested in debates internal to the view that do not speak to outside concerns about the plausibility of the view in any form. Nevertheless, whatever the value of such efforts, the present development does speak to those concerns, since it responds to a powerful external challenge to the plausibility of brute luck egalitarianism as a whole, showing that there is at least one plausible version of the view that is immune to that challenge.
} 
provides an obvious explanation why we should choose differently in the two cases, by appeal to the bearing of the different degrees of ex ante inequality under non-intervention on the badness of the disadvantage that would result from non-intervention in each case. Moreover, such a view has a certain amount of independent intuitive appeal. It has been endorsed by, among others, Arneson, Broome and Temkin. ${ }^{14}$ On the other hand, powerful doubts have been voiced about whether the ex ante view correctly diagnoses the source of our intuitions about the value of ex ante equality. Opponents of the view such as David Wasserman suggest that ex ante equality is valuable only as a way to ensure impartiality, and that a diagnosis of the value of ex ante equality in such terms provides no grounds for treating unequal outcomes that emerge from more ex ante equal distributions of chances as any less bad, or the reason to avoid unequal outcomes as any less strong, than unequal outcomes that emerge from less ex ante equal distributions of chances. ${ }^{15}$ It is also questionable, as I argue elsewhere, whether the ex ante view can accommodate intuitions about how we should respond to information that changes our judgements about probability, in a way that does not rely on a morally arbitrary distinction between changes to probability and eventuation of outcomes.

A second egalitarian response to the separateness of persons objection takes its lead from Andrew Williams's suggestion that prioritarians might respond to the objection by endorsing what he calls a 'restricted' version of prioritarianism, which applies only to cases involving interpersonal trade-offs. Along similar lines, one might think that egalitarians could respond to the objection by supposing that egalitarian considerations apply only when interpersonal trade-offs are involved. ${ }^{16}$ Such a view may appeal, in particular, to egalitarians who want to endorse the thought that, in the intrapersonal case, the fact that Albert has a chance of becoming better off than Bob does not provide any reason to intervene to preserve an equal outcome in that case. The problem for egalitarians, however, is that they are committed to measuring advantage and disadvantage in comparative terms. Unlike prioritarians, egalitarians care not about how well off or badly off agents are on some absolute scale, but about how unequally well off agents are. As such, the Williams-inspired response, even

14 R. J. Arneson, 'Postscript to "Equality and Equal Opportunity for Welfare"', Equality: Selected Readings, ed. L. Pojman and R. Westmoreland (Oxford, 1997), pp. 229-42, at 238-41; J. Broome, 'Fairness', Proceedings of the Aristotelian Society 91 (1990), pp. 87101, at 95; L. Temkin, 'Inequality: A Complex, Individualistic, and Comparative Notion', Philosophical Issues 11 (2001), pp. 327-53, at 338-9.

${ }^{15}$ D. Wasserman, 'Let Them Eat Chances: Probability and Distributive Justice', Economics and Philosophy 12 (2008), pp. 29-49.

${ }^{16}$ I thank a referee for Utilitas for suggesting this response. 
if a legitimate response to the separateness of persons objection for prioritarians, is simply not properly available to egalitarians. For on a comparative measure of advantage and disadvantage, there is an interpersonal trade-off to be made both in the intrapersonal case and in the interpersonal case. In order to say that there is no trade-off in the intrapersonal case, we would need to appeal to an absolute measure of advantage, such that we can say that Bob's level of absolute advantage will be unaffected by our choice. But since egalitarians are concerned with comparative measures of advantage, they cannot properly make such an appeal, without sliding unjustifiably between absolute and comparative measures of advantage. Instead, they must allow that, even in the intrapersonal case, Bob's level of comparative advantage will be affected by your choice, because all of the possible outcomes of non-intervention involve changes in both Albert's and Bob's levels of comparative advantage. ${ }^{17}$

Finally, consider the novel egalitarian solution to the separateness of persons objection suggested by Voorhoeve and Fleurbaey, and previously discussed by Otsuka and Voorhoeve: the so-called 'competing claims view'. According to the competing claims view, we are to:

decide between alternatives by considering the comparative strength of the claims of different individuals, where (i) a claim can be made on an individual's behalf if and only if his interests are at stake; and (ii) his claim to have a given alternative chosen is stronger: (iia) the more his interests are promoted by that alternative; and (iib) the worse off he is relative to others with whom his interests conflict. ${ }^{18}$

The competing claims view can respond to the separateness of persons objection by noting that, in the intrapersonal case, Albert has a presumptive claim in favour of non-intervention, whereas Bob, whose interests are not at stake, has no claim in favour of either option. In the interpersonal case on the other hand, Bob's claim in favour of intervention is to be weighed against Albert's claim against intervention, and Albert's potential loss in the interpersonal case

17 Even if this problem did not arise, one might further object on intuitive grounds that it is quite implausible that the fact that Albert has a chance of becoming better off than Bob does not provide any reason to intervene to preserve an equal outcome in the intrapersonal case, even though it would provide a reason to intervene in an otherwise identical modified case in which Bob will become ever so slightly better off if you choose intervention rather than non-intervention. Why should such a small difference in Bob's prognoses between the original intrapersonal case and the modified case make a disproportionately large difference to the bearing of Albert's prognoses on the permissibility of non-intervention?

18 Voorhoeve and Fleurbaey, 'Egalitarianism and the Separateness of Persons', p. 397. See also Otsuka and Voorhoeve, 'Why It Matters That Some Are Worse Off Than Others', pp. 183-4. 
acquires greater significance in this case because non-intervention will leave Albert worse off than Bob no matter what happens.

One attraction of the competing claims view over some other egalitarian responses to the separateness of persons objection is that it answers the objection in a way that at the same time avoids the levelling-down objection. ${ }^{19}$ But the significance of this virtue will depend on the degree to which one is troubled by the levelling down objection. Many egalitarians are not especially troubled by the objection, since they are happy to allow that levelling down might be in one way better than not levelling down, even though it will rarely be permissible because of the damage that levelling down would do to other values. ${ }^{20}$ The disadvantage of endorsing the competing claims view as an egalitarian response to the separateness of persons objection is that it remains unclear whether an account of this sort, which links deontic decisions to the relative weight of claims of individual agents, can provide a plausible account of how such claims are to be aggregated, although recent progress in the direction of such an account has certainly been made. ${ }^{21}$ Perhaps more problematically still, however, is the worry that the competing claims view provides no explanation for intuitions about how we should act in non-identity cases, and that to accommodate such cases we may need to appeal to the very sorts of principles that the competing claims view seeks to replace. ${ }^{22}$

In the light of the difficulties faced by other egalitarian responses to the separateness of persons objection, there is, then, every reason to examine the merits of further possible solutions. It is in this spirit that I argue in what follows that the hypothetical choice view provides not only a persuasive egalitarian response to the separateness of persons objection, but a view that ought to be appealing in its own right. One major advantage of the hypothetical choice view is that it avoids all of the foregoing objections to other egalitarian responses: it neither makes contested claims about the value of ex ante equality, nor slides inconsistently between comparative and absolute measures of disadvantage, nor faces difficulties with aggregation and non-identity cases. A drawback of the hypothetical choice view is that, unlike the competing claims view, but in common with the ex ante view, it does

19 Parfit, 'Equality and Priority', pp. 210-11.

20 See M. O’Neill, 'What Should Egalitarians Believe?', Philosophy \& Public Affairs 36 (2008), pp. 119-56, at 140-52.

21 For a recent discussion of the aggregation problem, which accommodates objections to some existing views, see A. Voorhoeve, 'How Should We Aggregate Competing Claims?', Ethics, forthcoming.

22 D. Parfit, Reasons and Persons (Oxford, 1986), ch. 16; see also Otsuka, 'Prioritarianism and the Separateness of Persons'. For a contractualist response, see R. Kumar, 'Who Can Be Wronged?', Philosophy and Public Affairs 31 (2003), pp. 99-118. 
not answer the levelling down objection. Nevertheless, as noted above, many egalitarians will be content with a pluralist response to the levelling down objection, and so will not regard this drawback as especially significant. Moreover, although I describe the hypothetical choice view in egalitarian terms, I note that prioritarians might also endorse a version of their view according to which distributive decisions ought to be sensitive to the hypothetical choices of agents affected by them. A prioritarian version of the hypothetical choice view would face neither the separateness of persons objection nor the levelling down objection, and so ought to be attractive to those who are exercised by both.

\section{THE HYPOTHETICAL CHOICE VIEW}

Brute luck egalitarians believe that disadvantage that is the result of unchosen circumstance is worse than disadvantage that is the result of choice. There is, however, another strand to early statements of brute luck egalitarianism, according to which hypothetical choices about risk ought also to bear on the evaluation of disadvantage, even in the absence of actual choice. Most notably, Dworkin's 'equality of resources' view - often taken as the first statement of brute luck egalitarianism, despite Dworkin's protests that he was not a luck egalitarian - held that those who develop handicaps should be compensated to the extent that the average person would have chosen to insure against such an eventuality. ${ }^{23}$ Even Cohen, to whom the now dominant focus on actual choice can largely be traced, accepted that hypothetical choice may have an important role to play in the evaluation of disadvantage. ${ }^{24}$ More broadly, of course, some of the most important figures in the recent and not-so-recent history of political thought - Rawls, Nozick and Rousseau, to name a few - have thought that hypothetical choice can do powerful normative work. ${ }^{25}$

I shall argue that brute luck egalitarians can avoid the separateness of persons objection if they endorse the view that, all other things being equal, disadvantage is worse when it results from a risk that the agent affected was unable to decline but would have declined if he had been able to do so, compared to disadvantage that does not result from such

${ }^{23}$ For example, R. M. Dworkin, Sovereign Virtue: The Theory and Practice of Equality (Cambridge, Mass., 2002), pp. 78-9, and R. M. Dworkin, 'Sovereign Virtue Revisited', Ethics 113 (2002), pp. 106-43, at 109-11.

${ }^{24}$ G. A. Cohen, 'On the Currency of Egalitarian Justice', Ethics 99 (1989), pp. 906-44, at $937-8$.

25 J. Rawls, A Theory of Justice, rev. edn. (Cambridge, Mass., 1999); R. Nozick, Anarchy, State, and Utopia (New York, 1974); J. Rousseau, The Social Contract and Other Later Political Writings (Cambridge, 1997). 
a risk. ${ }^{26}$ Moreover, I shall argue that such a view is not ad hoc, but is, rather, quite plausible for reasons independent of its ability to avoid the separateness of persons objection. Call this view the hypothetical choice view. ${ }^{27}$ Prioritarians could likewise develop their view in a similar direction, thereby also avoiding the separateness of persons objection. Whereas brute luck egalitarians read the hypothetical choice view as referring to comparative disadvantage, prioritarians could endorse the hypothetical choice view if they instead read it as referring to absolute disadvantage. Prioritarians could then claim that we have stronger reasons to choose an option to the extent that agents disadvantaged by the option (in absolute terms) would not have declined to choose the option, had they been able to do so, without at the same time endorsing the claim made by hypothetical-choice brute luck egalitarianism that these stronger reasons derive from judgements about the relative badness of possible unequal outcomes. ${ }^{28}$ Nevertheless, for clarity, and because, unlike prioritarians, brute luck egalitarians have not yet responded to the separateness of persons objection, I frame the article in terms of a brute luck egalitarian version of the hypothetical-choice view.

Despite the limited use of hypothetical choice in early formulations of brute luck egalitarianism, the hypothetical choice view nevertheless

${ }^{26}$ As I noted above, actual choice luck egalitarians think that disadvantage that results from choice can be as bad as disadvantage that results from unchosen luck if the choice was not made against appropriate background conditions, such as in the presence of a reasonable alternative. We might therefore extend the hypothetical choice view to say that disadvantage is worse when it results from a risk that either the agent affected was unable to decline and would have declined if he had been able to do so, or that the agent chose in the absence of appropriate background conditions but would have declined had the appropriate background conditions obtained, compared to disadvantage that does not result from such a risk. The addition has no bearing on the present response to Voorhoeve and Fleurbaey, however, since their example features agents who are straightforwardly unable to choose for themselves whether to face a risk.

27 The hypothetical choice view of present interest is not the same as the view that hypothetical choices render agents agent-responsible, in something like the sense that an agent should be seen as the author of anything that he would have chosen. The latter claim is the object of a powerful critique by S. L. Hurley, Justice, Luck, and Knowledge (Cambridge, Mass., 2005), pp. 28-30. The two views are different, first, because the view of present interest makes no claims about agent responsibility, but only about the badness of disadvantage; second, because the present view is concerned only about hypothetical choices about risks that in fact lead to actual disadvantage, whereas the view that Hurley critiques claims that agents are agent responsible for both actual and hypothetical outcomes that they would have chosen or chosen to risk, that is, regardless of whether or not the outcome that they would have chosen or chosen to risk actually eventuates.

${ }^{28}$ Arneson has argued that prioritarians ought to be sensitive to responsibility and choice, though he does not mention hypothetical choice in these articles (but see $n$. 34 below). R. J. Arneson, 'Equality of Opportunity for Welfare Defended and Recanted', Journal of Political Philosophy, 7 (1999), pp. 488-97; R. J. Arneson, 'Luck Egalitarianism and Prioritarianism', Ethics 110 (2000), pp. 339-49. 
amounts to a significant departure from currently mainstream versions of brute luck egalitarianism. There is some work to be done, then, to show that the hypothetical choice view is not merely an ad hoc technical fix to the separateness of persons objection, but a view that ought to be attractive to brute luck egalitarians for independent reasons. ${ }^{29}$

One way of arguing for the hypothetical choice view is simply to show that it provides an accurate description of our intuitions about test cases. In order to develop such an argument, consider the following two scenarios, both of which are versions of Voorhoeve and Fleurbaey's Two-Person Intrapersonal case. The pay-off matrices for the agents featuring in each scenario are identical to that described in Voorhoeve and Fleurbaey's original case. The only difference is that Albert's attitude to risk varies across the scenarios. In scenario one, Albert would not decline intervention if he were able to do so, whereas in scenario two, Albert would decline intervention if he were able to do so. ${ }^{30}$ Call the Albert of scenario one, who would not decline intervention, Cautious Albert, and the Albert of scenario two, who would decline intervention, Incautious Albert. Suppose further that Bob, who features both in scenario one and in scenario two and whose sight would remain unaffected in both cases, has no preference between intervention and non-intervention in either scenario. At the time the opportunity for intervention arises, Cautious Albert and Incautious Albert are, for reasons entirely beyond their control, neither able to convey their preferences to you nor able to intervene in the natural course of events themselves. Perhaps, for example, their voices are drowned out by the roar of a passing aircraft. Suppose that, in ignorance of both Cautious Albert's and Incautious Albert's preferences, you decide

29 The hypothetical choice view of present interest shares with the Dworkinian hypothetical insurance view a focus on hypothetical choice, but nevertheless differs from the Dworkinian view in that it does not apply a hypothetical insurance approach to risks that agents would have faced behind a veil of ignorance. Rather, the hypothetical choice view of present interest applies only to risks that agents actually confront in the real world. As such, the present view avoids the ongoing dispute between those who charge that the Dworkinian hypothetical insurance view can lead to implausibly inegalitarian results, by virtue of facts about the things that agents in general would and wouldn't choose to insure against from behind a veil of ignorance, and those who deny that it does so. See J. E. Roemer, 'Equality of Talent', Economics and Philosophy 1 (1985), pp. 151-88; M. Fleurbaey, 'Equality of Resources Revisited', Ethics 113 (2002), pp. 82-105; Dworkin, 'Sovereign Virtue Revisited', pp. 129-36.

${ }^{30}$ If one supposes - as Voorhoeve and Fleurbaey do not - that utility ought to be measured in terms of rational preferences that satisfy the Von Neumann-Morgenstern axioms, then it would be irrational of Albert to decline intervention. But even if Albert's hypothetical choice would be irrational, he might nevertheless be inclined so to choose, and there is no reason why the hypothetical choice view should treat only ideally rational hypothetical choices as relevant to the badness of disadvantage. Certainly actual-choice brute luck egalitarianism does not standardly insist that choices must be ideally rational in order to render disadvantage less bad than it would otherwise have been. 
neither to intervene in the natural course of events that poses a risk to Cautious Albert, nor to intervene in the natural course of events that poses a risk to Incautious Albert. As a result, when the two natural courses of events unfold, Cautious Albert and Incautious Albert end up suffering a worsening of their visual impairment. They are each thereby disadvantaged by comparison with Bob.

According to the hypothetical choice view, the fact that Cautious Albert would have declined the risk that led to his disadvantage, whereas Incautious Albert would not have done so, means that the disadvantage suffered by Incautious Albert is not as bad as the disadvantage suffered by Cautious Albert. I think that this is right. To draw out this intuition, suppose that you now learn that Incautious Albert would have declined intervention whereas Cautious Albert would not have done so. Suppose further that you also learn that one dose of a new medicine is available, which you can use to restore either Cautious Albert's visual impairment or Incautious Albert's visual impairment to the state it was in before the natural course of events caused it to worsen. It seems quite plausible that, with nothing else to choose between the two, the fact that Cautious Albert would have declined to face the risk whereas Incautious Albert would not have declined to face the risk does provide a reason to give the medicine to Cautious Albert rather than Incautious Albert. The underlying ground for this intuition, one might reasonably conclude, is that the disadvantage suffered by Cautious Albert is worse than the disadvantage suffered by Incautious Albert. That the hypothetical choice view supplies a ready explanation for the intuition is a point in its favour over the other egalitarian responses canvassed in section III, which do not provide any explanation for the stated intuition.

Against the preceding argument, one might object that there is an alternative explanation of the intuition that you should give the medicine to Cautious Albert rather than to Incautious Albert, which makes no reference to a difference in the badness of Cautious Albert's and Incautious Albert's disadvantage. The alternative explanation is compatible with, albeit not supplied by, the other egalitarian responses canvassed above. ${ }^{31}$ According to the alternative explanation, we ought to give the medicine to Cautious Albert over Incautious Albert for the following reason. Now that we know that Incautious Albert would have declined intervention, we know that we chose exactly as Incautious Albert would have wanted. On the other hand, now that we know that Cautious Albert would not have declined intervention, we know that we did not choose as Cautious Albert would have wanted. We may

${ }^{31}$ I am grateful to a referee for Utilitas for suggesting this alternative explanation. 
further think that, had we known at the time that Cautious Albert would not have declined intervention, then we would have been obliged to choose intervention on his behalf. For it is plausible that the riskregarding preferences of agents make a difference to how we should treat them because, for example, of autonomy-type reasons, or because we should make decisions about other agents based, at least in part, on a preference-based measure of utility. ${ }^{32}$ As such, we might conclude that we are now obliged to do the next best thing for Cautious Albert, which is to give him the medicine to restore his sight.

How successful is this alternative explanation of the intuition that you should give the medicine to Cautious Albert rather than to Incautious Albert? I am dubious about the general principle to which the explanation appeals, namely, something like the principle that 'if you would at some earlier time have been obliged to act contrary to how you in fact acted, had you then known what you now know, then all other things being equal you should now act so as to bring about as close as possible a state of affairs to that which would have emerged had you acted in accordance with the hypothetical obligation'. But even if we were to accept a principle along these lines, the suggested alternative explanation still faces a further problem. The difficulty is that the alternative explanation cannot explain why you should give the medicine to Cautious Albert over Incautious Albert in a modified scenario, identical to the present one except that the possibility of intervention - either by yourself or by anybody else - never in fact existed. (Had the possibility of intervention existed, Cautious Albert would have chosen it, whereas Incautious Albert would have declined it.) Since the original explanation in terms of the badness of disadvantage can accommodate both the original and the modified case, we have reason to prefer it to the alternative explanation.

A second way to argue for the hypothetical choice view, which adds strength to the intuitive case but does not depend on the intuitive case, is to show that it is an accurate reflection of an underlying brute luck egalitarian concern with the impact of unchosen circumstance. One reason, perhaps, that brute luck egalitarians have tended to focus on actual choice rather than hypothetical choice is that actual choice appears more obviously to reflect this underlying concern. If we can show that hypothetical choices ought also to bear on this underlying concern, then such a finding should considerably enhance the appeal of the hypothetical choice view to brute luck egalitarians.

To see how hypothetical choices can bear on an underlying concern with the impact of unchosen circumstance, consider that there are

32 Cf. Williams, ‘The Priority View Bites the Dust?', p. 320, n. 19. See section VI below for discussion of whether such considerations matter in cases that involve children. 
two quite different ways of understanding the concern. One way focuses exclusively on the actual causal sequence that leads from the unchosen circumstance to the disadvantage: if the sequence is sufficiently tight, and/or uninterrupted by some relevant exercise of agency on the part of the disadvantaged agent (or, perhaps, some wrongdoer), then the disadvantage is regarded as appropriately linked to the unchosen circumstance. This way of understanding a concern with the impact of unchosen circumstance does not provide grounds for treating hypothetical choice as relevant to such a concern. But there is another way of understanding the concern, according to which what matters is not only the actual causal sequence, but also what would have happened had the unchosen circumstance not occurred. This second interpretation is at least as plausible a reading, if not a more plausible reading, of the brute luck egalitarian concern with the impact of unchosen circumstance. In support of this claim, notice that it is commonplace, across many areas of morality and law, that the impacts of offending acts, omissions and circumstances are identified, at least in part, relative to what would have happened otherwise. In tort, for example, the liability of a defendant may be assessed in part by reference to what would have happened had the tort not occurred.

Now, to the extent that brute luck egalitarians ought to interpret their concern with the impact of unchosen circumstance in terms of what would have happened otherwise, they ought to treat hypothetical choices as sometimes bearing on this underlying concern. To see this, consider again the (unmodified) case of Cautious Albert and Incautious Albert. In both cases, we will want to say that the disadvantage experienced by Cautious Albert and the disadvantage experienced by Incautious Albert are, at least in part, impacts of unchosen circumstance. For had the natural course of events been otherwise, and had you not decided not to intervene in the natural course of events, then the outcomes that the agents now experience might in both cases not have occurred. This is true regardless of the fact that Cautious Albert would have chosen intervention whereas Incautious Albert would have declined intervention. But there is a third respect in which the disadvantage now experienced by Cautious Albert is the impact of a further unchosen circumstance, whereas the same cannot be said - if we understand impact in terms of what would have happened otherwise - of the disadvantage now experienced by Incautious Albert. For the disadvantage now experienced by Cautious Albert is also partly the impact of the unchosen circumstance that Cautious Albert was unable either to express to you his preference for intervention or to intervene in the natural course of events himself. Had he been able to express his preference for intervention, or to intervene himself, he might not have suffered a worsening of his visual impairment. 
In the former case, where Cautious Albert is able to express his preference for intervention but not to intervene himself, it is reasonable to assume that, all other things being equal, you would have acted on the basis of Cautious Albert's preference. The assumption about how you would have acted in the former case is warranted because it is plausible that, as discussed above, the risk-regarding preferences of agents make a difference to how we should treat them, and it is reasonable to suppose that knowledge of this fact would have caused you to choose differently had you known Cautious Albert's preference. Moreover, even if one doubts that knowledge of Cautious Albert's preference would - or should - have affected your choice, it remains the case that Cautious Albert's disadvantage is also partly the impact of the unchosen circumstance that he was unable to intervene in the natural course of events himself. Whether or not knowledge of Albert's preference would have affected your choice, it is certainly reasonable to suppose that, all other things being equal, had Cautious Albert been able to intervene himself, he would have acted on the basis of his preference for intervention. On the other hand, the same cannot be said of Incautious Albert, who would still have suffered a worsening of his visual impairment even if he had been able to express his preference for non-intervention and if you had acted on the basis of that preference, or if it had been Incautious Albert himself who was in the position to intervene but declined to do so. ${ }^{33}$ In this respect, then, the disadvantage that Cautious Albert experiences is, to a greater extent than the disadvantage that Incautious Albert experiences, the impact of unchosen circumstance. ${ }^{34}$

In the present section I have argued for two claims. First, I have argued that the hypothetical choice view is intuitively plausible. Second, I have argued that the hypothetical choice view can be regarded as an expression of the underlying brute luck egalitarian concern with the impact of unchosen circumstance. The case for the hypothetical

${ }^{33}$ If we understand counterfactuals in terms of possible worlds, my claim is that of the possible worlds in which Incautious Albert is able to choose for himself, the closest such possible world to the actual world (in which Incautious Albert is not able to choose for himself) is one in which Incautious Albert suffers a worsening of his visual impairment because he chooses non-intervention. My claim is not that of any possible world other than the actual one, the closest possible world to the actual world is one in which Incautious Albert is able to choose for himself. The former claim is plausible. The latter is not.

34 Arneson assumes, but does not develop, something like the present position in a brief argument directed against Brian Barry's equal opportunity principle. Arneson writes that 'If I was bound and determined not to take an umbrella to the picnic in any case, my claim to compensation from society due to losses I suffer when rain spoils my picnic is not enhanced if in fact there was no umbrella available for me to take, given that the umbrella option would have had no impact on events in any case.' See R. J. Arneson, 'Does Social Justice Matter? Brian Barry's Applied Political Philosophy', Ethics 117 (2007), pp. $391-412$, at 399 . 
choice view does not depend on the second claim, although, as I noted above, it is certainly strengthened by it.

\section{HOW THE HYPOTHETICAL CHOICE VIEW AVOIDS THE SEPARATENESS OF PERSONS OBJECTION}

The hypothetical choice view can accommodate the intuition that it is permissible to choose non-intervention in Voorhoeve and Fleurbaey's Two-Person Intrapersonal case, but not in their Two-Person Interpersonal case. To see how it does so, consider in turn the various risks faced by Albert and Bob in the two cases. First, consider the risks faced by Albert and Bob in the intrapersonal case. Bob does not face any risk in this scenario. Whether or not you intervene, Bob's visual impairment will remain unchanged. Albert, on the other hand, will face a risk of disadvantage if you choose non-intervention. He will face the risk that his visual impairment will worsen, though he will also have a chance of becoming fully sighted. In the absence of any information to the contrary, it is reasonable to assume that, if Albert could exercise choice about the matter, then he would not decline to face the risk associated with non-intervention. Such an assumption is warranted because the expected utility of non-intervention is, for Albert, higher than the expected utility of intervention. ${ }^{35}$

Now consider the interpersonal case. In this scenario, if you choose non-intervention, then Bob will stand a chance of becoming fully sighted, with no possibility of disadvantage on his part. Albert, on the other hand, will face the risk that his visual impairment might become worse, with no possibility of improvement. In the absence of any information to the contrary (such as extreme altruism towards Bob on Albert's part ${ }^{36}$ ), it is reasonable to suppose that Albert would decline to face this risk if he were able to choose to do so.

35 If we adopt a Von Neumann-Morgenstern measure of utility, and if you know that Albert has informed, ideally rational, self-interested preferences, then you can do better than assume that Albert would choose non-intervention over intervention. In that case, you can know that, because the utility of non-intervention is higher than that of intervention, it is true as a matter of definition that Albert would choose (or at least would prefer) non-intervention over intervention. But even if those conditions don't obtain, the reasonable assumption nevertheless suffices to justify non-intervention.

${ }^{36}$ Even then, one might doubt whether a hypothetical choice grounded in such altruism should justify treating the disadvantage as less bad than it would otherwise have been. For discussion of the role of altruism in brute luck egalitarianism, see N. Eyal, 'Egalitarian Justice and Innocent Choice', Journal of Ethics and Social Philosophy 2 (2007), pp. 1-18; Z. Stemplowska, 'Making Justice Sensitive to Responsibility', Political Studies 57 (2009), pp. 237-59, at 244-5; S. Olsaretti, 'Responsibility and the Consequences of Choice', Proceedings of the Aristotelian Society 109 (2009), pp. 165-88, at $180-1$. 
Overall, then, it is reasonable to suppose that Albert would not decline to face the risk of being disadvantaged by non-intervention in the intrapersonal case, but that Albert would decline to face the risk of being disadvantaged by non-intervention in the interpersonal case. As such, according to the hypothetical choice view, non-intervention would lead to disadvantage in the interpersonal case that would be in one, in this case decisive, way expectably worse than the disadvantage generated by non-intervention in the intrapersonal case. This is because, in the interpersonal case, non-intervention would involve exposing an agent, Albert, to a risk of disadvantage that one could reasonably expect that he would decline if he were able to do so, whereas in the intrapersonal case, non-intervention would not involve exposing an agent to a risk of disadvantage that one would reasonably expect him to decline.

Notice that, in defending the claim that the hypothetical choice view can accommodate the difference between Voorhoeve and Fleurbaey's intrapersonal case and their interpersonal case, I have discussed only the bearing of Albert's hypothetical choices about risk on the badness of Albert's disadvantage. But, one might object, in the interpersonal case it is also the case that Bob, unlike Albert, would not have declined the risk: ought this fact not also make a difference to the badness of Albert's disadvantage? If so, then the hypothetical choice view might be forced to say that Albert's disadvantage is, after all, no worse in the interpersonal case than in the intrapersonal case, and therefore to leave unanswered the separateness of persons objection. Nor can brute luck egalitarians simply respond that Albert's hypothetical choices bear on the badness of Albert's disadvantage or advantage, whereas Bob's hypothetical choices bear on the badness of Bob's disadvantage or advantage, but that the hypothetical choices of one agent do not bear on the badness of another agent's disadvantage or advantage. This is because the egalitarian focus on comparative disadvantage and advantage, or inequality, means that, as discussed in section III above, brute luck egalitarians cannot simply separate out Albert's and Bob's disadvantage and advantage in the envisaged way. As Otsuka and Voorhoeve put it, for brute luck egalitarians, 'badness inheres in the relational property of some being less well off than others': the badness cannot then be separated into two distinct parcels, one of which is Albert's and the other of which is Bob's. ${ }^{37}$

There is a problem here, but it is certainly not unique to the hypothetical choice view, nor to my claim that the hypothetical choice

37 Otsuka and Voorhoeve, 'Why It Matters That Some Are Worse Off Than Others', p. 183. 
view can answer the separateness of persons objection. For it is well known that brute luck egalitarianism, even in its actual-choice form, needs somehow to accommodate the fact that an inequality-generating event might have been chosen by one agent affected by the inequality but not chosen by another agent affected by the inequality. ${ }^{38}$ One common way that brute luck egalitarians try to avoid this problem - which I have implicitly adopted in the present article - is to focus on the choices, and by extension the hypothetical choices, of those who are disadvantaged (rather than advantaged) by a particular risk that disadvantages some and advantages others. Another option would be to say that the badness of disadvantage resulting from risk depends partly on how many of the agents affected by the inequality chose, or would not have declined, to face the risk. Both of these formulations face difficulties, and I believe that it is, for the time being at least, an open question whether or not either of them, or some other formulation, can succeed. But if either of the formulations does succeed, then Bob's hypothetical choice in the interpersonal trade-off case would not pose a problem for my claim that the hypothetical choice view can answer the separateness of persons objection, because on neither formulation would Bob's hypothetical choice in the interpersonal tradeoff case prevent the hypothetical choice view from treating Albert's potential disadvantage as worse in the interpersonal case than in the intrapersonal case. On the other hand, if they do not succeed, and if no other formulation can be supplied which accommodates the fact that an inequality-generating event might have been chosen by one agent affected by the inequality but not chosen by another agent affected by the inequality, then brute luck egalitarianism is already in very deep water, even before the separateness of persons objection makes an entrance. Notice that Bob's hypothetical choice in the interpersonal trade-off case would not raise any of these difficulties for a hypothetical choice version of prioritarianism. The disadvantage with which such a view is concerned is not comparative, so it would be much easier for such a view to say that only Albert's hypothetical choice, and not also Bob's hypothetical choice, is relevant to the badness of the disadvantage that Albert stands to suffer in the interpersonal trade-off case.

${ }^{38}$ For example, G. A. Cohen, 'Fairness and Legitimacy in Justice, and: Does Option Luck ever Preserve Justice?', in G. A. Cohen, On the Currency of Egalitarian Justice, and Other Essays in Political Philosophy, ed. M. Otsuka (Princeton, 2011), pp. 124-44, at 143; D. Miller, 'The Incoherence of Luck Egalitarianism', University of Oxford CSSJ Working Papers Series, SJ022 (2014). 


\section{CHILDREN}

One might agree that there is sometimes a role for hypothetical choice in fixing the badness of disadvantage, but deny that hypothetical choice plays any role in fixing the badness of disadvantage in Voorhoeve and Fleurbaey's examples. One might so deny because, in Voorhoeve and Fleurbaey's examples, Albert and Bob are both children. Along similar lines, Voorhoeve and Fleurbaey endorse the thought in Otsuka and Voorhoeve's earlier article that, because the rational capacities of (young) children are underdeveloped, and because their preferences are ill-informed, 'there is no reason to defer to whatever wishes [they] may have out of respect for [their] autonomy'. ${ }^{39}$ The hypothetical choice view does not claim that we should defer to agents' wishes out of respect for their autonomy: it makes a claim about the bearing of hypothetical choices on the badness of disadvantage, which the autonomy view does not make, and the hypothetical choice view need not appeal to the value of autonomy to justify its claim, as described above. Nevertheless, one might think that the fact that the agents are children militates not only against deferring to their wishes out of respect for autonomy, but also against treating their choices and hypothetical choices as relevant to the evaluation of disadvantage in the manner recommended by the hypothetical choice view. If that is the case, then the hypothetical choice view may not after all be able to render egalitarianism compatible with intuitions about the moral relevance of interpersonal boundaries in these and other cases involving children.

I think that the concern about children is overstated. For one thing, we might ask what justifies Voorhoeve and Fleurbaey's stipulations about Albert's and Bob's levels of advantage in various situations if not facts about their preferences. To be sure, Voorhoeve and Fleurbaey do not themselves insist that Albert's and Bob's levels of advantage ought to be measured by reference to an actual-preference-based measure of utility, but it is nevertheless commonly thought that preferences ought to play an important role in measuring levels of advantage, and Voorhoeve and Fleurbaey do not argue against the use of such a measure in the case of children. For another thing, we do commonly hold children responsible for some of their choices at least, even though we may suspect that the preferences on which those choices are based are not all that well formed. Indeed, one of the main reasons that we do so is precisely to facilitate children's development into responsible agents, by encouraging them to take seriously their role as choice-bearers by developing better-formed preferences. I grant, however, that such a

39 Voorhoeve and Fleurbaey, 'Egalitarianism and the Separateness of Persons', p. 384; Otsuka and Voorhoeve, 'Why It Matters That Some Are Worse Off Than Others', p. 88. 
response might not be applicable to cases like the present one, in which particularly severe consequences are at stake.

Even if we should not treat the hypothetical choices of children as bearing on the badness of disadvantage they suffer, there is an obvious way in which the hypothetical choice view could be modified slightly to accommodate examples involving children. For consider that, where we do think that children's preferences ought not to be foregrounded, the moral role that would normally be played by choices and preferences in the case of adults is instead played by interests in the case of children (or perhaps, not dissimilarly, by assumptions about what rational guardians would choose for their charges). One might therefore develop a view according to which disadvantage in the case of children is worse when it results from a risk that it was expectably damaging to the selfinterest of the children affected, considered individually, to be exposed to, than when it results from a risk that it was not expectably damaging to the self-interest of the children affected, considered individually, to be exposed to (or when a rational guardian with his or her charge's interests in mind would have declined to expose his or her charge to the risk). Such a view can explain the difference in our intuitions about the two-person intrapersonal case and the two-person interpersonal case, even if the fact that Albert and Bob are children renders their hypothetical choices irrelevant to an evaluation of the badness of their disadvantage. It can do so because non-intervention is expectably damaging to Albert's interests in the two-person interpersonal case, but expectably damaging to neither agent's interests in the two-person intrapersonal case. Note that the justification for such a view would not appeal to hypothetical choices of children or to the value of autonomy, since the view does not suppose that the children will prefer that which is in their interests. Rather the justification would be something like the thought that, if you have a pro tanto duty not to do something which you know will be expectably damaging to a child's interests, considered individually (or which a rational guardian would have declined for their charge), then all other things being equal the disadvantage that a child suffers as a result of your acting contrary to that duty is worse than it would have been had you chosen in a way that was in conformity with the duty. This could be true even if your choice was all things considered permissible or even required as a result of competing duties to other children, whose interests may also have been at stake in your decision. ${ }^{40}$

40 Note that neither the interests view nor the hypothetical choice of guardians view is threatened by Voorhoeve and Fleurbaey's 'Principle of Full Information', according to which you should not rank options based on agents' ex ante interests, or based on what guardians who do not know which outcome will eventuate would choose for their 


\section{CONCLUSION}

Voorhoeve and Fleurbaey charge that brute luck egalitarians, in common with utilitarians and prioritarians, cannot accommodate intuitions about the moral relevance of interpersonal boundaries. Such intuitions are exemplified by the difference in the intuitive permissibility of non-intervention in their Two-Person Intrapersonal case and their Two-Person Interpersonal case. In response to this challenge, I have argued that brute luck egalitarians can accommodate intuitions about the moral relevance of interpersonal boundaries by endorsing the hypothetical choice view, which claims that hypothetical choices about risk play a role in fixing the badness of disadvantage. Such a view, I argued, is not ad hoc, but is plausible independently of its ability to answer the separateness of persons objection. I also noted that those who are drawn to prioritarianism might likewise endorse a version of their view that is sensitive to hypothetical choices. I argued that, even if the hypothetical choice view does not apply in cases involving children, nevertheless a modified version of the view can still accommodate intuitions about the separateness of persons in such cases. Of course the hypothetical choice view still confronts many of the objections that have been posed against existing formulations of brute luck egalitarianism, including the worry that brute luck egalitarianism cannot accommodate the fact that an inequality-generating event might have been chosen by one affected agent but not chosen by another affected agent, and its shift in focus away from actual choice doubtless invites new objections. Those who are especially exercised by such objections will not be persuaded by the hypothetical choice view. Nevertheless, others will be more troubled by the difficulties that alternative responses to the separateness of persons objection face-by, for example, Wasserman's worries about the ex ante view, and by the acknowledged incompleteness of the competing claims view. For these readers, the hypothetical choice view offers an attractive explanation of the intuitions to which Voorhoeve and Fleurbaey direct our attention. ${ }^{41}$

\section{k.d.hyams@warwick.ac.uk}

charges, if for any possible outcome you would rank the options differently if you knew what the outcome was going to be. They are not threatened because, as Fleurbaey and Voorhoeve themselves grant, the Principle of Full Information does not apply when, as in the present cases, one would rank the outcomes differently depending on which outcome occurs. A. Voorhoeve and M. Fleurbaey, 'Decide as You Would with Full Information! An Argument against ex ante Pareto', Inequalities in Health: Concepts, Measures, and Ethics, ed. N. Eyal, S. Hurst, O. Norheim and D. Wikler (Oxford, 2013), pp. 113-28.

${ }^{41} \mathrm{I}$ am grateful to Alex Voorhoeve and an anonymous referee for comments on a previous version of this article, and to the AHRC for funding the research. 